\title{
Design of the Hybrid Regenerative Shock Absorber and Energy Harvesting from Linear Movement
}

\author{
Mustafa Demetgul and Ismail Guney
}

\begin{abstract}
Shock absorbers or dampers are used to maintain the contact between the vehicle's tires and road surface, to absorb the vibrations generated from the road disturbances and recently they are used in energy harvesting. In this study, a hybrid regenerative shock absorber system containing hydraulic and electromagnetic (EM) damper mechanisms was designed to generate electricity. The energy harvesting was applied from the hybrid regenerative shock absorber using excited linear movement. A total of $0.25 \mathrm{~W}$ for $0.004 \mathrm{~m} / \mathrm{s}, 0.4 \mathrm{~W}$ for $0.0045 \mathrm{~m} / \mathrm{s}$ and $0.66 \mathrm{~W}$ for $0.005 \mathrm{~m} / \mathrm{s}$ was harvested using $80 \Omega$ and $2 \Omega$ external resistors for hydraulic part and for EM part, respectively, at $15 \mathrm{~mm}$ amplitude in response to the specified excitation. The mean power for $0.005 \mathrm{~m} / \mathrm{s}$ was calculated as $0.003 \mathrm{~W}$ for coil and as $0.56 \mathrm{~W}$ for generator. The harvested energy was measured as low for measured velocities, however, the amount of harvestable energy rate or efficiency has increased with increasing velocity.
\end{abstract}

Index Terms-Electromagnetic damper, energy harvesting, shock absorber, hydraulic damper, regenerative damper.

\section{INTRODUCTION}

Energy harvesting or recovering has been more popular topic recently with ever increasing environmental pollution. The countries, particularly, automobile manufacturers have intensified their researches on the low emission and energy efficient vehicles [1]. Besides, many countries around the world have extensively supported the studies of heat, bioenergy and vibration energy recoveries [1]-[8].

Shock absorbers or dampers are the mechanical devices that designed to absorb the shocks and minimize the vibrations. They are also used to maintain the contact between the vehicle's tires and road surfaces [9], [10]. Many studies have been carried out on making shock absorbers much more efficient in performance [9]-[11]. For the last 25 years, shock absorbers have been a considerable issue in energy-regenerative systems. The different techniques were applied to the road disturbances to generate electricity [12]-[14]. As for vehicles, it is mentioned that around 10$16 \%$ of the fuel energy is employed to overcome the resistances such as air drag, road friction and vibrations [15]. Over the years, traditional suspension systems have been significantly developed. For example, the relative linear movement between sprung and unsprung mass was changed into the movement of electric motor rotor [16]. The hybrid suspension and various linear transmission systems were began to be used. However, these technologies are still far away from the usage of commercial purposes [10].

Manscript received June 8, 2015; revised December 17, 2015.

The authors are with the Department of Mechatronics Engineering, Faculty of Technology, Marmara University, Istanbul, 34722, Turkey (e-mail: mdemetgul@marmara.edu.tr, ismail.guney@marmara.edu.tr).
Studies of power potential in regenerative vehicle suspension have reported a range of harvestable energy values between $46 \mathrm{~W}$ and $7500 \mathrm{~W}$ using different techniques [8]-[10], [12]-[15]. In a different study, Kawamoto et al. [17] reported a model in which $15.3 \mathrm{~W}$ energy was recovered from one of the shock absorbers of a vehicle at $50 \mathrm{mph}$ on the $\mathrm{C}$ class road with a vibration above $2 \mathrm{~Hz}$. Zhang et al. [18] obtained $11.7 \mathrm{~W}$ energy from regenerative suspension system of a real car with three-phase motor under randomly excited condition. Zuo and Zhang [9] recovered an average of 100$400 \mathrm{~W}$ energy from the suspensions of a middle-sized car at $60 \mathrm{mph}$ on the good and average roads. Li et al. [14] captured $114.1 \mathrm{~W}$ energy on average from hydraulic regenerative suspension system with harmonic excitation at $8 \mathrm{~mm}$ amplitude, $2 \mathrm{~Hz}$ frequency and $7.5 \Omega$ optimal external resistor. Chen and Liao [19] designed a magnetorheological damper which integrated the dynamic sensing, damping and energy harvesting, and they harvested around $0.1 \mathrm{~W}$ energy from this system. Li et al. [20] proposed a motion rectifier in regenerative suspension system, which is composed of one shaft, three bevel gears, two roller clutches, two racks and one pinion. They recovered $15 \mathrm{~W}$ electricity from the smooth-paved road at $15 \mathrm{mph}$ speed. Moreover, very recently, Levant Power Corporation [21] designed two 'GenShock' prototypes for energy harvesting and active damping control. Fang [22] developed a hydraulic electromagnetic shock absorber or HESA for energy recovery and damping studies.

It is possible to convert vibration/kinetic energy to electric energy by using regenerative shock absorber effectively. The harvested energy from automotive shock absorbers will result in a much more economical vehicle performance in terms of fuel consumption as well as it will decrease the amount of $\mathrm{CO}_{2}$ emission ranging from $1.4 \mathrm{~g} / \mathrm{km}$ to $5 \mathrm{~g} / \mathrm{km}$ [23].

The studies of hydraulic and EM shock absorbers have demonstrated that external electrical circuit is integrated to the system to observe the harvested energy and damping properties of shock absorbers [14], [24]-[27].

Fang et al. [22] have measured the pressure of hydraulic circuit from four different points; (1) upper and (2) lower chamber of hydraulic cylinder, and (3) inlet and (4) outlet of hydraulic motor. They have observed the similar sinusoidal pressure fluctuations for three measured points including 1-3 while point 4 demonstrated a slightly higher value than zero with relatively stable fluctuations. It has been reported that even tiny pressure fluctuations in hydraulic systems could readily turn the oil bubble into liquid, which cause to produce unwanted noises and give damages to the internal parts of damper [29]. Therefore, pressure fluctuations in hydraulic circuits have to be regularly checked.

In this study, a new type of hybrid energy-regenerative suspension system has been proposed and examined at three 
different velocities by using tensile test machine. This new hybrid system includes the combined hydraulic and electromagnetic structures.

\section{MATERIAL AND METHODS}

Prototype of shock absorber was designed using CAD software SolidWorks 2015 (SolidWorks Corp, Concord, Mass.), and manufactured (scaled 3:2) as monolithic. The device is composed of two main parts; conductor (1) and translator (2). The conductor consists of cylinder and coil, while translator consists of rod/piston mechanism composed of permanent magnets and poles (Fig. 1).

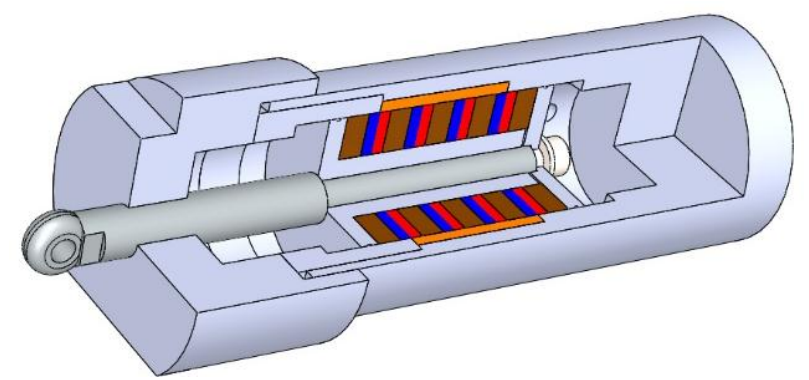

Fig. 1. Half-section view of the hybrid regenerative damper.

\section{A. Hydraulics}

The approximately 6 bars hydraulic packing pressure was applied to the system, considering the internal diameter of the cylinder chamber is $D_{1}=70 \mathrm{~mm}$, the diameter of shaft of the piston is $D_{2}=20 \mathrm{~mm}$. The connection between shock absorber and hydraulic circuit, and other hydraulic components is provided by using standard self-closing couplings. The bidirectional movement on the two divisions of shock absorber's cylinder was directed into one way rotation by the four check valves of the hydraulic circuit. Thus, the hydraulic circuit with check valves was used to derive one-way flow. Without check-valves-circuit, hydraulic and DC motors could be seriously affected. Because instant bidirectional movements of hydraulic and DC motors cause the mechanical and electrical problems under high frequency excitation. The unidirectional rotation was employed to drive a gearbox to enhance the number of revs per minute (ratio 15:1). Enhanced speed rotations was subsequently transferred to generator to harvest the energy. In addition, hydraulic circuit contains an accumulator which stabilize the instant load shocks and stores the oil as volume as with parallel changing rod volume.

\section{B. Electromagnetics}

There are three general known topologies for permanent magnet machines such as (i) moving coil, (ii) moving iron, and (iii) moving magnet. Among these topologies, moving magnet topology/configuration has been reported to be the most suitable configuration [30]. Therefore, we preferred the moving magnet topology/configuration. The stator of damper or cylinder contains the windings, which are cylindrical coil. The translator or rod contains the machine's permanent magnets. In this study, four sintered neodymium magnets $\mathrm{N} 35$, five poles (spacers), and a copper wire coil were used to build moving magnet topology/configuration. N35 has the following properties; the remanence or residual flux density of the permanent magnets (PM): $B_{\text {rem }}=1.42 \mathrm{~T}$; the coercivity force of the permanent magnets: $H_{c}=900 \mathrm{kA} / \mathrm{m}$ and maximum operating temperature: $T_{\max }: 80^{\circ} \mathrm{C}$. For coil, the following parameters/properties were adapted; the number of turns per coil: $700\left(\rho_{c u}=1,7 \times 10^{-8} \Omega-\mathrm{m}\right)$ and the measured total resistance of the coil: $2 \Omega$. Later, and the wired coil was attached in cylinder as monolithic.

\section{Energy Harvesting System}

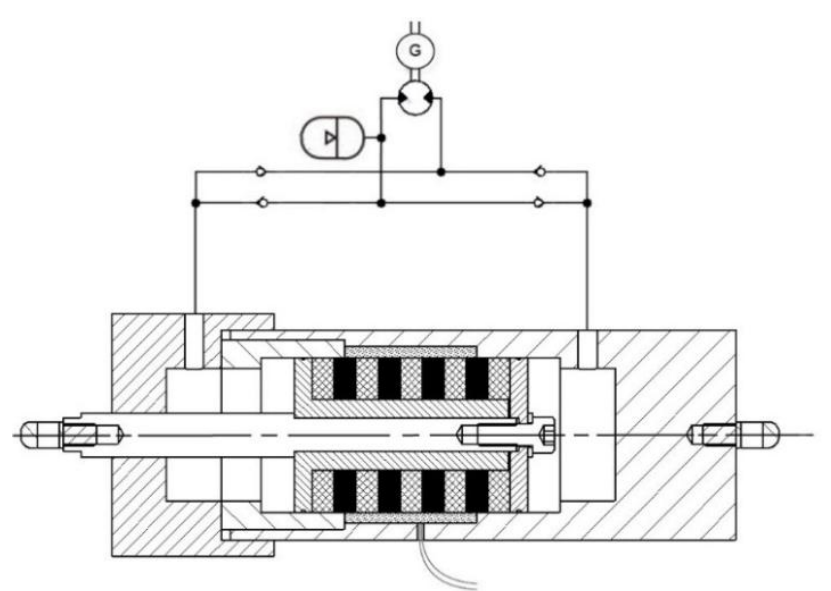

Fig. 2. Schematic of the proposed energy-harvesting shock absorber.

The energy harvesting system contained the hydraulic and electromagnetic (EM) mechanisms, and electric circuits (Fig. 2-Fig. 3). The external circuit was integrated to the system to observe the harvested energy properties of shock absorbers. To obtain the optimum harvesting energy from the regenerative shock absorber, the value of external resistors of system was chosen as equal to the internal resistors of the coil and generator [14], [24]-[28]. The constant resistors were used as the load of the energy harvesting system.

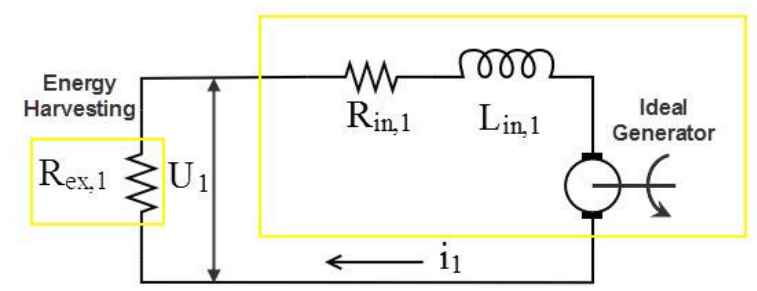

(a)

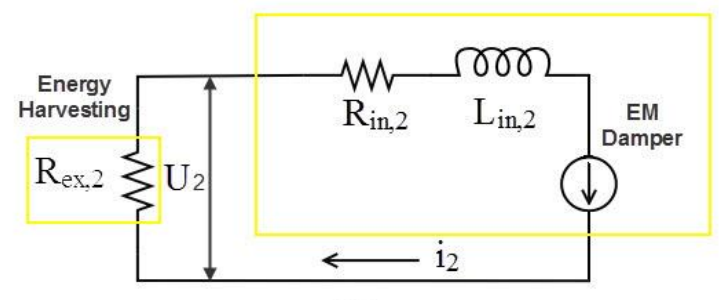

(b)

Fig. 3. Diagrams of electrical circuits for (a) generator and (b) stator coil.

Following formulas were used to calculate the output of generated power;

The circuit equation of the output voltage:

$$
U_{(t)}=e_{(t)}-L_{\text {in }} \times \frac{d i}{d t}-R_{\text {in }} \times i_{(t)}
$$

The voltage on the external resistor (for each resistor):

$$
U_{(t)}=R_{e x} \times i_{(t)}
$$


The total current for each circuit:

$$
i_{(t)}=\frac{U_{(t)}}{R_{e x}}
$$

The harvested power $P_{(t)}$ of each circuit:

$$
P_{(t)}=U_{(t)} \times i_{(t)}
$$

Or, The harvested power $P_{(t)}$ of each circuit using equation (3):

$$
P_{(t)}=\frac{U_{(t)^{2}}}{R_{e x}}
$$

The total harvested power of system:

$$
\Sigma P_{(t)}=\frac{U_{1}{ }^{2}}{R_{e x, 1}}+\frac{U_{2}^{2}}{R_{e x, 2}}
$$

\section{Experimental Setup}

In this section, the prototype was tested as shown in Fig. 4. The designed prototype was fixed on the universal tensile testing machine (FU $50 \mathrm{kN}$, Devotrans, Turkey) that was controlled by a desktop computer via a controller. The testing machine was driven by a DC motor. The pressure of inlet of hydraulic motor fluctuations were measured by using Barksdale pressure transmitter (having range 0-100 bar). The output voltage of the energy-harvesting shock absorber was recorded by the oscilloscope, Rigol DS 1104B containing four channels.

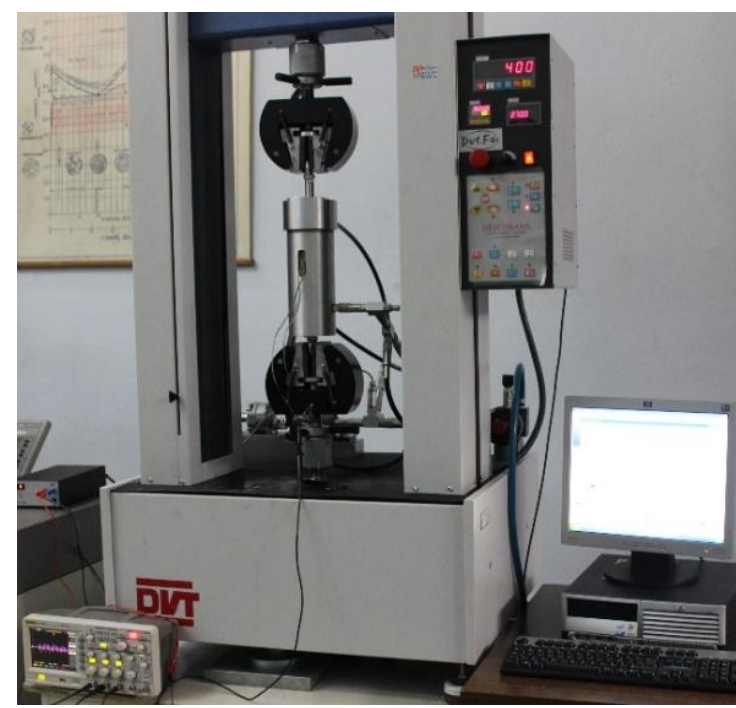

Fig. 4. Experimental setup for hybrid regenerative shock absorber.

\section{RESULTS}

This paper proposes a novel hybrid energy-regenerative suspension system which integrates the combined hydraulic and electromagnetic mechanisms. We performed the energy harvesting test at three different velocities such as 0.004 , 0.0045 and $0.005 \mathrm{~m} / \mathrm{s}$. In previous studies of energy harvesting, the range of testing velocities were mainly chosen between $0-0.3 \mathrm{~m} / \mathrm{s}$ [14], [28], [30]. However, in this study, the velocity values were chosen as low to analyse the systemic errors and leakages at low velocities. A total of $0.25 \mathrm{~W}$ for $0.004 \mathrm{~m} / \mathrm{s}, 0.4 \mathrm{~W}$ for $0.0045 \mathrm{~m} / \mathrm{s}$ and $0.66 \mathrm{~W}$ for $0.005 \mathrm{~m} / \mathrm{s}$ was harvested using $80 \Omega$ and $2 \Omega$ external resistors for hydraulic part and for EM part, respectively, at $15 \mathrm{~mm}$ amplitude in response to the specified excitation. The mean power for $0.005 \mathrm{~m} / \mathrm{s}$ and $15 \mathrm{~mm}$ amplitude was calculated as $0.003 \mathrm{~W}$ for coil and as $0.56 \mathrm{~W}$ for generator (Fig. 5 and Fig. $6)$. It was observed that for the measured velocities, as the speed increases, the amount of harvestable energy rate or efficiency increases. In addition, we have analysed the pressure fluctuations in the system because even tiny pressure fluctuations in hydraulic systems could produce unwanted noises and give damages to the internal parts of damper. Pressure fluctuations were measured as max. 18 bar and min. $\sim 0$ bar in a system with 6 bar packing pressure (Fig. 7).

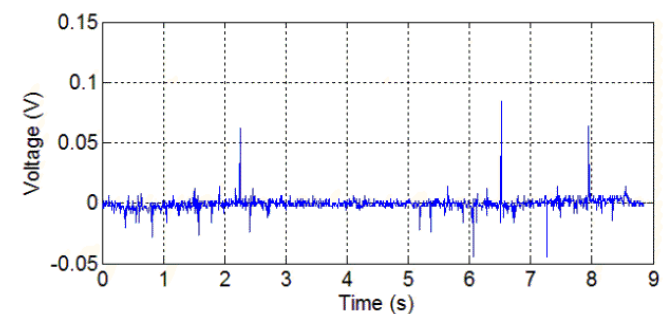

(a)

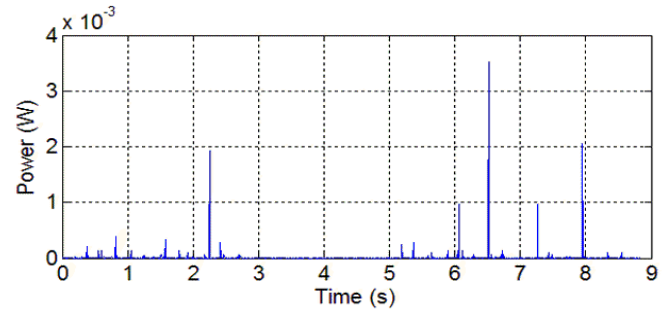

(b)

Fig. 5. Electrical responses of EM part in the system as gained (a) voltage and (b) harvested power.

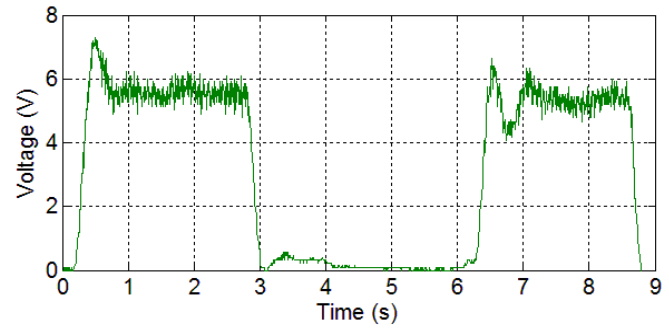

(a)

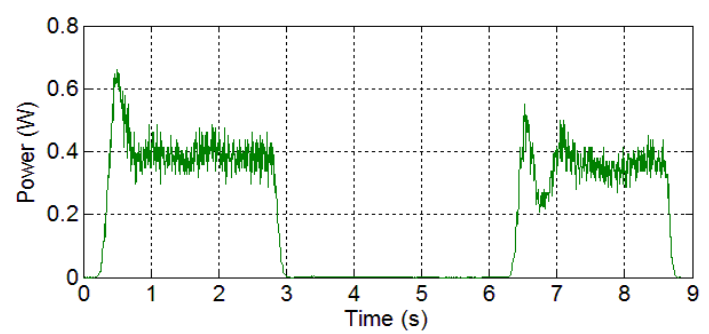

(b)

Fig. 6. Electrical responses of hydraulics part in the system as gained, (a) voltage and (b) harvested power.

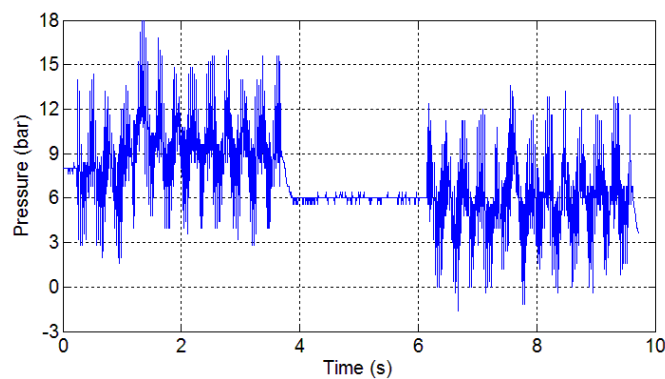

Fig. 7. Pressure fluctuations on extension and compression strokes. 


\section{DISCUSSION}

In studies of energy harvesting from regenerative EM shock absorbers, the value of external load is mainly accepted as equal to the equivalent coil (internal) resistance to optimize the power transfer. However, to gain the optimum power transfer for regenerative hydraulic shock absorbers, the values of external load are generally chosen different than those of internal load of generator at $0 \mathrm{rpm}$. Nevertheless, the values of external load are chosen close to the values of internal load of generator at $0 \mathrm{rpm}$. Therefore, we have not used different load values, because we have assumed that those values will result in optimum harvested power. The harvested energy was measured as low, however, for the measured velocities, the amount of harvestable energy rate or efficiency has increased with increasing velocities. Many studies have reported that when the speed increases, the amount of harvestable energy rate or efficiency increases [14], [28]. Therefore, our results were consistent with previous studies.

Overall, this study is a preliminary work but results are encouraging. The next phase of our research will therefore centre on the different experimental conditions, including higher speed excitations. As a future work, structural analysis and parameter optimization of this hybrid system are planned.

\section{ACKNOWLEDGMENT}

This work was supported by the Marmara University's Research and Project Department under the grant FEN-C-YLP-121114-0362.

\section{REFERENCES}

[1] N. V. Satpute, S. Singh, and S. M. Sawant, "Energy harvesting shock absorber with electromagnetic and fluid damping," Advances in Mechanical Engineering, vol. 6, 2014.

[2] A. P. C. Faaij, "Bio-energy in Europe: Changing technology choices," Energy Policy, vol. 34, no. 3, pp. 322-342, 2006.

[3] I. N. Tansel et al., "Design of energy scavengers of structural health monitoring systems using genetically optimized neural network systems," Sensors and Materials, vol. 21, no. 3, pp. 141-153, 2009.

[4] S. Korla et al., "Design and testing of an efficient and compact piezoelectric energy harvester," Microelectronics Journal, vol. 42, no. 2, pp. 265-270, 2011.

[5] S. Singh and N. V. Satpute, "Design and analysis of energy-harvesting shock absorber with electromagnetic and fluid damping," Journal of Mechanical Science and Technology, vol. 29, no. 4, pp. 1591-1605, 2015.

[6] M. Demetgül, "Design of energy harvesters with Taguchi optimization techniques," FCRAR 2009, Florida, USA.

[7] Y. Zhang et al., "Study on a novel hydraulic pumping regenerative suspension for vehicles," Journal of the Franklin Institute, vol. 352, no. 2, pp. 485-499, 2015.

[8] Y. Suda and S. Taichi, "A new hybrid suspension system with active control and energy regeneration," Vehicle System Dynamics, vol. 25, pp. 641-654, 1996.

[9] L. Zuo and P.-S. Zhang, "Energy harvesting, ride comfort, and road handling of regenerative vehicle suspensions," Journal of Vibration and Acoustics, vol. 135, no. 1, 2013.

[10] X. Lin et al., "Simulation and performance evaluation of hydraulic transmission electromagnetic energy-regenerative active suspension," in Proc. 2010 Second WRI Global Congress on Intelligent Systems, 2010, vol. 3.

[11] S. Aubouet et al., "A LPV control approach for a semi-active hydraulic damper," in Proc. 11th Mini Conference on Vehicle System Dynamics, Identification and Anomalies, 2009

[12] A. Gupta et al., "Design of electromagnetic shock absorbers," International Journal of Mechanics and Materials in Design, vol. 3, no. 3, pp. 285-291, 2006.
[13] C. K. Wai and Y. R. Yong, "Electric vehicle energy harvesting system regenerative shock absorber for electric vehicle," in Proc. 2013 IEEE Conference on Sustainable Utilization and Development in Engineering and Technology, 2013.

[14] C. Li et al., "Integration of shock absorption and energy harvesting using a hydraulic rectifier," Journal of Sound and Vibration, vol. 333, no. 17, pp. 3904-3916, 2014.

[15] R. A. Oprea et al., "Design and efficiency of linear electromagnetic shock absorbers," in Proc. 2012 13th International Conference on Optimization of Electrical and Electronic Equipment, 2012.

[16] D. A. Weeks et al., "The design of an electromagnetic linear actuator for an active suspension," SAE Technical Paper, No. 1999-01-0730. 1999.

[17] Y. Kawamoto et al., "Modeling of electromagnetic damper for automobile suspension," Journal of System Design and Dynamics, vol. 1, no. 3, pp. 524-535, 2007.

[18] Y. C. Zhang et al., "Experimental verification of energy-regenerative feasibility for an automotive electrical suspension system," in Proc. IEEE International Conference on Vehicular Electronics and Safety, 2007.

[19] C. Chen and W.-H. Liao, "A self-sensing magnetorheological damper with power generation,” Smart Materials and Structures, vol. 21, no. 2, 2012.

[20] Z. Li et al., "Energy-harvesting shock absorber with a mechanical motion rectifier," Smart Materials and Structures, vol. 22, no. 2, 2013.

[21] J. Mossberg et al., "Recovering energy from shock absorber motion on heavy duty commercial vehicles," SAE Technical Paper, No. 2012-01-0814, 2012

[22] Z. G. Fang et al., "Experimental study of damping and energy regeneration characteristics of a hydraulic electromagnetic shock absorber,"Advances in Mechanical Engineering, vol. 5, 2013.

[23] M. Willems, "Estimation of the recuperation potential of shock absorber energy," ATZ Worldwide, vol. 114, no. 9, pp. 28-32, 2012.

[24] B. Ebrahimi et al., "A hybrid electromagnetic shock absorber for active vehicle suspension systems," Vehicle System Dynamics, vol. 49, no. 1-2, pp. 311-332, 2011.

[25] L. Barbara et al., "Analysis, design and simulation of an electromechanical energy harvesting system using a linear movement," in Proc. 2014 International Conference on Green Energy, 2014.

[26] B. Lafarge et al., "Modeling of an electromechanical energy harvesting system using an linear movement," JNRSE, 2013.

[27] L. Zuo et al., "Design and characterization of an electromagnetic energy harvester for vehicle suspensions," Smart Materials and Structures, vol. 19, no. 4, 2010.

[28] Z. J. Li et al., "Electromagnetic energy-harvesting shock absorbers: design, modeling, and road tests," IEEE Transactions on Vehicular Technology, vol. 62, no. 3, pp. 1065-1074, 2013.

[29] J. Dixon, The Shock Absorber Handbook, John Wiley \& Sons, 2008.

[30] R. Palomera-Arias, "Passive electromagnetic damping device for motion control of building structures," Ph.D. dissertation, Massachusetts Institute of Technology, 2005.

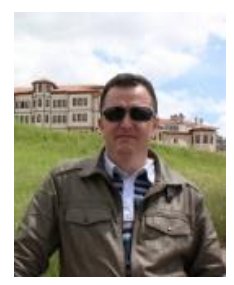

Mustafa Demetgul was born in Duzce, Turkey, in 1978. He received the B.Sc. and M.S. degrees in mechanical, and the Ph.D. degree in mechanical from Marmara University, Istanbul, Turkey. From 2007 to 2009, he was a postdoc with the Mechanical Engineering Department, Florida International University, Florida, USA. He currently works at the Department of Mechatronics Engineering, Marmara University as an Assoc. Prof. Dr. His research interests are fault diagnosis, energy harvesting, automation systems, structural health monitoring and artificial intelligence systems. He is the director of Fault Diagnosis and Structural Health Monitoring Lab in Marmara University.

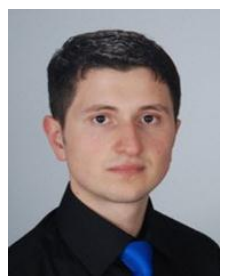

Ismail Guney was born in Bursa, Turkey, in 1990. He received his B.Sc. degree in mechanical from Marmara University, Istanbul, Turkey and in mechanical engineering from Sakarya University, Sakarya, Turkey. He is currently pursuing the M.Sc. degree and works as a research assistant at the Department of Mechatronics Engineering, Marmara University. His research interests are regenerative shock absorbers, manufacturing technologies and 